\title{
Measuring the Impacts of Employer-based Transportation Demand Management Programs on an Interstate Corridor
}

Nevine Labib Georggi, Phil Winters, Sachin Rai, and Liren Zhou Center for Urban Transportation Research, University of South Florida

\section{Abstract}

This article is based on a study that analyzed the impacts of employer-based transportation demand management (TDM) strategies and the performance of a transportation system. The study simulated the effects of the Washington State Commute Trip Reduction (CTR) programs implemented by 189 employers on an 8.6-mile segment of $1-5$ in the Seattle downtown area. This comprehensive dataset included before/after employer trip reduction plans and the origins/destinations of nearly 63,000 commuters working for those 189 employers. The current performance of the selected network was compared to that of a scenario with reduced vehicle trips due to CTR programs added back onto the network. The hypothesis of the research was that a widescale adoption of employer-based strategies is likely to have a measurable difference on the performance of a transportation system. The analysis found the reduction in AM peak delay due to TDM programs implemented in the study area was 152,489 vehicle-minutes and 17,297 vehicle-miles of travel. Savings in PMpeak delay were 169,486 vehicle-minutes and 14,510 vehicle-miles were reduced. Fuel saved in the AM and PM peaks were 3,489 and 4,314 gallons, respectively. Some segments and periods saw significant improvement. The study proved that compre- 
hensive TDM programs could have a significant impact on the operation of a major Interstate corridor.

\section{Introduction}

Traffic congestion continues to affect the quality of life in the United States. According to the Texas Transportation Institute's (TTI) 2005 Annual Urban Mobility Report, "Despite a slow growth in jobs and travel in 2003, congestion caused 3.7 billion hours of travel delay and 2.3 billion gallons of wasted fuel, an increase of 79 million hours and 69 million gallons from 2002 to a total cost of more than $\$ 63$ billion" (Schrank and Lomax 2005). These impressive numbers directly correlate to degradation of transportation system efficiency and performance. In recognition of the challenges facing communities, Schrank and Lomax recommend a balanced approach including-beginning to "plan and design major capacity increasing projects, plans or policy changes while immediately relieving critical bottlenecks and aggressively pursuing operations improvements and demand management options that are available." One of the questions that quickly arises is what can transportation demand management (TDM) contribute.

Numerous case studies assessing the impacts of TDM report significant changes in travel behavior and vehicle miles of travel or vehicle trips reduced (VTR) but not the performance effects on any particular corridor. At the University of California's Los Angeles campus, transit ridership for commuting to campus increased by 56 percent during the first year promotion of an unlimited access pass program, and solo driving fell by 20 percent. Since the pass program reduced the demand for parking by at least 1,020 spaces, the reduction in parking demand was worth $\$ 32.1$ million (1,020 spaces $\times \$ 31,500$ per space; Brown 2003).

The U.S. General Services Administration (GSA) estimates that 80 percent of federal agencies adopt alternate work schedules such as telework or compressed workweek (GSA 2005). From 2003 to 2004 the number of teleworkers increased 37 percent $(102,921$ to 140,694$)$. The number of employees teleworking as a percentage of those eligible to telework (41\%) increased from 14 percent in 2003 to 19 percent in 2004. Thirty-eight agencies (46\%) reported that more than 25 percent of their workforce participated in telework during 2004. Not considering other alternatives, such as compressed workweek or flex hours that remove vehicle trips off the peak hours of congestion, these hard numbers are a result of only one strategy, teleworking, that totally eliminated vehicle trips from the road. 
If these thousands of government workers were to join in daily peak-hour traffic, then levels of transportation system congestion, air quality, lost time, vehicle miles traveled (VMT), and fuel consumption would dramatically worsen. In 2004, South Florida Commuter Services, the regional commuter assistance program that serves Miami-Dade, Broward, and Palm Beach Counties in South Florida, reported 2.2 million vehicle trips and 57,660,000 VMT reduced due to its ridematching and vanpool programs (Hagelin and Perone 2004).

The scale of the employer-based programs is another issue. Though the programs may, in total, substantially reduce VMT, the reductions are likely to be spread geographically and temporally so the "observed" impact may be difficult to recognize. However, substantial investments have shown significant overall impacts. The state of Washington invested $\$ 2.7$ million in CTR programs in 2005. This investment, combined with those of local jurisdiction partners and participating employers, provided significant benefits for the state's citizens that were quantified as follows in the annual report (Commute Trip Reduction Task Force 2005):

- at least \$24 million in reduced cost of delay in the Puget Sound region (calculated using 2003 data)

- savings of $\$ 13.7$ million in fuel costs for employees commuting to CTR worksites based on driving fewer miles

- reduction of 3,700 tons of criteria pollutants including carbon monoxide, volatile organic compounds, and oxides of nitrogen

- reduction of the equivalent of 74,200 tons of carbon dioxide

For traffic operations and transportation planners, the question is how do these impressive reductions change the performance of the traffic network? There is no recognized process for performance measurement that captures the actual impacts of employer-based TDM programs on a transportation system. This research study combined two common goals of transportation agencies: relieving congestion and increasing the efficiency of the transportation system. By monitoring, evaluating, and communicating TDM strategies and their combined impacts on the roadway system, planners, traffic operations staff, TDM professionals, decision makers, and elected officials can be "on the same page" choosing to combine and compare all the available cost-effective measures to reduce congestion. 


\section{Literature Review}

In reviewing different performance measurement efforts on the state level, the Florida Commuter Assistance Program (CAP) evaluation measures included (CUTR 1999):

- number of commuters requesting assistance

- number of commuters switching modes

- number of vans in service (where applicable)

- number of vehicle trips eliminated

- vehicle miles eliminated

- employer contacts

- parking spots saved/parking needs reduced

- commuter costs saved

- major accomplishments

- gasoline saved

- emissions reduced

- information materials distributed

- special events

- media/community relations

It seems logical that CAP's results would correlate to improvements in transportation system efficiency and performance. What remains to be done is translating these measures of effectiveness (MOEs) into measurable congestion improvements on a traffic system.

There is a similar challenge in addressing how to relate the impact of worksite trip reduction programs on the transportation system as well as on the worksite level. For example, the CTR program in Washington State has used a variety of methods to help communicate the impacts in its biennial reports to the state legislature (CTR Task Force 2005). In 1999, a lane-mileage reduction method was used to estimate low-cost additional roadway capacity and reduced trip times for motorists and freight that had resulted from removing vehicles trips due to CTR. In 2001, WSDOT used change in travel delay. In 2003, the agency used a method developed by TTI for its 2003 Annual Urban Mobility Report (Schrank and Lomax 2003). This methodology estimated the levels of congestion on roadways in major metropolitan areas throughout the country. 
TTI's 2003 report used a new methodology to estimate the delay reduction from five congestion remedies: ramp metering, incident management, signal coordination, public transportation, and high occupancy vehicle (HOV) lanes. These analysis techniques are experimental but provide a context for understanding the significance and value of travel delay reduction. TTI estimated that the total (morning and evening) annual delay reduction in 2003 for changes in commute choices at CTR sites was 1.84 million hours and valued the savings at \$24 million each year. In addition, fuel savings from less stop-and-go traffic amounted to an estimated 3.6 million gallons - worth more than $\$ 5.8$ million per year to commuters. The TTI methodology for estimating delay and speed for various congestion mitigation strategies is based on a macroscopic approach. Travel delay is estimated from vehicle traffic per lane and traffic speed equations. The fundamental challenge is to assess the bearings of TDM programs on the traffic system and to quantify speed, delay, and travel time after TDM programs are applied.

The research study addressed this challenge by using a microscopic simulation model, CORSIM, to evaluate the impacts of employer-based programs from the WSDOT CTR database on a segment of Seattle's downtown I-5 corridor. The implications of the research can be instrumental in developing strategies that increase transportation system efficiency, particularly by reducing delays and bottlenecks during peak hours without added construction costs.

The process begins with the selection of pertinent performance measures. On the national level, the National Transportation Operations Coalition (NTOC) Action Team on Performance Measurement was assembled to define and document "a few good measures" for transportation operations performance measurement (NTOC 2005). With the guidance of an oversight team comprised of transportation professionals and state and local government representatives, specific measures focused on the following issue areas:

- nonrecurring congestion (e.g., traffic incident management)

- recurring congestion (e.g., arterial management, traffic signal timing)

- system-wide performance (e.g., travel time, reliability, congestion)

The oversight team identified performance measures within each of these areas. These measures, listed below, were defined as commonly acceptable and important among a range of jurisdictions and agencies. NTOC recommended standardizing these performance measures. This research study utilized several of these 
measures (underlined in the list below), in addition to other MOEs, including vehicle miles reduced, fuel savings, and vehicle emission reduction to communicate the impacts of TDM on the transportation system.

- customer satisfaction

- spatial extent of congestion (lane miles)

- temporal extent of congestion (hours of congestion)

- incident duration (median minutes per incident)

- nonrecurring delay (vehicle-hours)

- recurring delay (vehicle-hours)

- average speed (miles per hour)

- person throughput (minutes)

- vehicle throughput (vehicle per hour)

- travel time-link (minutes per trip)

- travel time-reliability (buffer time in minutes)

- travel time-trip (minutes per trip)

\section{Research Methodology}

The literature review revealed the gap between methodologies used to evaluate the effectiveness of employer-based TDM strategies at worksites and common measures used to evaluate the performance of the transportation system. The research study addressed this gap by developing a methodology that will help TDM professionals communicate the effectiveness of employer-based programs in terms of commonly used transportation performance measures, including delay in vehicle-hours and seconds per vehicle, average speed in miles per hour ( $\mathrm{mph}$ ), spatial and temporal extent of congestion, in addition to fuel consumption in gallons and emissions in grams/mile. The hypothesis of the research was that a widescale adoption of employer-based strategies is likely to have a measurable impact on the performance of a transportation system.

The methodology was to simulate the impacts of employer-based programs affecting a segment of a corridor to compare traffic performance with and without TDM programs. The steps summarized below were followed: 
1. A traffic network with documented data of employer-based TDM programs in its surroundings was selected.

2. Worksites utilizing TDM programs within the impact area were inventoried.

3. Time period for the analysis was defined.

4. Data including worksite information, types of employer-based TDM strategies practiced, employee participation, and employee commute travel behavior were collected.

5. VTR at each worksite were calculated.

6. VTR were then distributed (pairs of origin-destination trips) on the traffic network.

7. The distributed trips were then assigned onto network links based on the shortest path between origins and destinations.

8. The already-calibrated microsimulation model was run with existing volumes (Scenario A: with TDM).

9. VTR (from step 7) were added to existing traffic counts on network links (Scenario B: without TDM).

10. Scenarios A and B were run and data from output files were analyzed to compare the scenarios.

\section{Employer-based TDM Programs Data}

In 1991, the Washington State Legislature passed the CTR law (RCW 70.94.521551) to reduce traffic congestion, air pollution, and petroleum consumption through employer-based programs that reduce peak-hour, single-occupant vehicle (SOV) commute trips in the states' nine most populous counties. The CTR program works with employers to encourage workers to commute without driving alone every day and encourages transportation service providers to expand the opportunities available to employees for commuting in ways other than driving alone. The results of these efforts are demonstrated in the daily choices made by more than 560,000 employees at the 1,114 worksites participating in the program. CTR employers submit an annual report and a program description form to report on TDM programs implemented. CTR employers are also required to survey employee commute behavior every two years to measure progress toward their CTR goals. The employer annual report and employee biennial survey form two 
databases that provide detailed data on the employers' TDM performance and employees' travel behavior. The data are detailed, comprehensive, and certified as correct for each employer. Information contained in the annual employer report includes:

- worksite description

- employee information

- program promotion information, including list of CTR programs implemented or promoted by the employer

- worksite characteristics

- worksite parking information and parking management

- financial incentive and subsidies

- site amenities

- work schedule policy

- other programs' availability [e.g., guaranteed ride home (GRH), internal match, fleet vehicle, etc.]

Information contained in the individual employee survey includes:

- work schedule

- commute trip mode split

- compressed workweek schedule

- teleworking schedule

- travel distance

- job title

- home zip code

\section{Traffic Network Data}

The study corridor was selected in the vicinity of a high concentration of CTR-participating employers where quality data are regularly collected. The Washington State CTR program database for the year 2003 was studied to establish the geographical concentration of participating employers. The database provided the list of cities and zip codes with high numbers of employers/employees participating in 
TDM programs. The WSDOT long-range plans were studied to determine where DOT has identified problem areas and planned future improvements.

Based on these factors, $1-5$ in downtown Seattle was selected as the transportation corridor for this study. Figure 1 shows worksite locations on and around the 1-5 study area. The area consists of 8.6 miles of I-5 from NE 45th Street in the north to Corson Avenue in the south. The 67 lane-miles of interstate consist of 16 onramps and 19 off-ramps. Other major roadways in the area were I-90, SR 520, and SR 99. The $1-5$ reversible express lanes were not considered in the analysis as they provided limited entrance to and egress from the study area or provided access to HOV lanes only. The total volumes of the three-hour AM peak between 6:00 AM and 9:00 AM were 22,500 and 19,900 vehicles for the northbound and southbound 1-5, respectively, for the year 2004. The three-hour PM-peak volumes between 3:00 PM and 6:00 PM were 19,800 and 20,600 vehicles for northbound and southbound

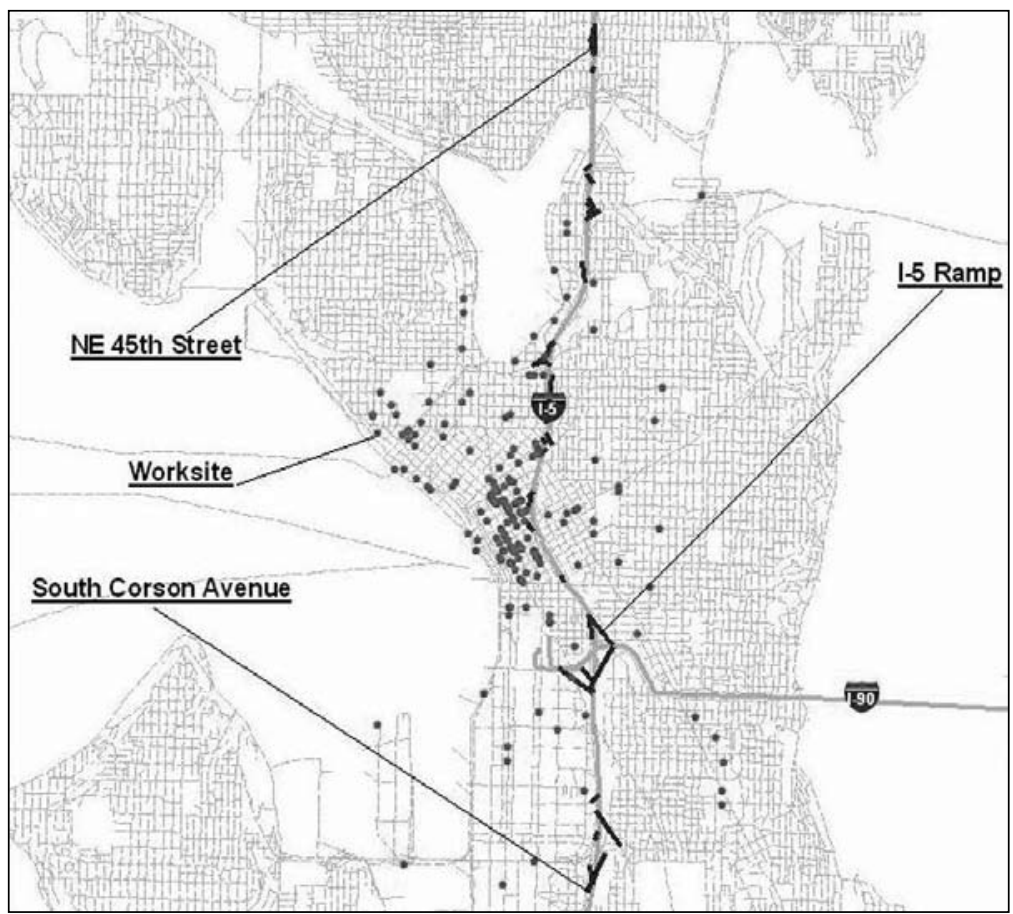

Figure 1. Employer Worksites in Study Area of I-5 
1-5, respectively. The study area had 189 employers participating in CTR programs, affecting 62,947 employees.

\section{Traffic Analysis Tool: CORSIM}

CORSIM, a stochastic microsimulation model, has been used by practitioners and researchers for the past 30 years to simulate and conduct various transportation-related evaluations. CORSIM assigns random numbers to drivers, vehicle characteristics, and decision-making processes simulating the randomness of the actual traffic conditions. The model has different driver types, depending on the aggressiveness of driving, various vehicle types, and vehicle fleets, depending on the acceleration capability, weight, and size of vehicles. All proportions of these driver types and vehicle types can be adjusted to simulate the existing driver and vehicle mix. Several calibration parameters can be modified to adjust the model for the existing traffic conditions. These parameters include mean start-up delay at ramp meters, incident rubbernecking factors, car-following sensitivity factors, lane change gap acceptance dynamics, and factors affecting discretionary lane changes.

The CORSIM network model files for the AM- and PM-peak periods were obtained from the WSDOT with traffic volume data for the year 2004. The network files were already calibrated by WSDOT to represent the traffic conditions that exist on the field. The volumes were provided in 19 time intervals of 15 minutes each from 5:30 AM to 10:15 AM for the AM peak and from 3:00 PM to 7:45 PM for the PM peak. The transportation network consists of nodes and links in the CORSIM network file where nodes are intersections, location of exits on interstate, or location of merge-on interstates; and links are actual roadways between two nodes. An 8.6-mile segment of the $1-5$ corridor was divided into 49 links in CORSIM to simulate the changes in the roadway geometry, add/drop lanes, or ramps on the Interstate.

\section{The Analysis}

\section{Trip Reduction Estimation, Distribution, and Assignment}

Since the CTR employee biennial survey is conducted after the CTR program is implemented, it is assumed for this study that individual employee commute travel behavior information in the survey is the scenario with TDM. However, 
since the implementation of TDM programs vary across the employers, the definition of with TDM was not consistent. In other words, the scenario with TDM for one employer may differ from another. It is possible to define the scenario with TDM assuming all target employers implement the same level of TDM program. The shortcoming of this assumption would be the lack of the corresponding employee commute travel behavior data. The reality is that employers comply with the same CTR law in various degrees.

While TDM is a broad application of different strategies aimed at reducing and/or eliminating SOVs, for the purposes of this research, these strategies are combined into four different groups and only the impact of these groups will be evaluated (Table 1).

\section{Table 1. Combined Groups of TDM Strategies for Scenarios A and B}

\begin{tabular}{|l|l|l|l|l|}
\hline Group & \multicolumn{1}{|c|}{ Strategies } & \multicolumn{1}{|c|}{ Purposes } & \multicolumn{1}{|c|}{$\begin{array}{l}\text { Scenario A } \\
\text { With TDM }\end{array}$} & \multicolumn{1}{|c|}{$\begin{array}{l}\text { Wcenario B } \\
\text { Without TDM }\end{array}$} \\
\hline A & $\begin{array}{l}\text { Alternative } \\
\text { work } \\
\text { schedules }\end{array}$ & CWW and telecommuting. & $\begin{array}{l}\text { This group of strategies } \\
\text { functions to reduce } \\
\text { person trips. }\end{array}$ & $\begin{array}{l}\text { Employees are not } \\
\text { allowed to } \\
\text { telecommute or } \\
\text { participate in CWW. }\end{array}$ \\
\hline B & $\begin{array}{l}\text { Employer } \\
\text { TDM support } \\
\text { strategies }\end{array}$ & $\begin{array}{l}\text { Nonmonetary promotions to encourage use of } \\
\text { alternative modes. These include rideshare } \\
\text { matching services, vanpool formation } \\
\text { assistance, onsite transit information and/or } \\
\text { pass sales, ETCs, and guaranteed ride home. }\end{array}$ & $\begin{array}{l}\text { This group of strategies } \\
\text { functions to reduce } \\
\text { drive-alone trips by } \\
\text { encouraging employee } \\
\text { taking alternative } \\
\text { modes. }\end{array}$ & $\begin{array}{l}\text { Employers do not assist } \\
\text { in any way to } \\
\text { encourage modes } \\
\text { other than SOV. }\end{array}$ \\
\hline C & $\begin{array}{l}\text { Travel cost } \\
\text { changes }\end{array}$ & $\begin{array}{l}\text { Measures such as imposition of parking fees, } \\
\text { differential rates or discounts for carpool or } \\
\text { vanpool parking, transit fare subsidies }\end{array}$ & $\begin{array}{l}\text { This group of strategies } \\
\text { functions to reduce } \\
\text { SOVs by increasing } \\
\text { SOV costs or } \\
\text { decreasing that of } \\
\text { alternative modes. }\end{array}$ & $\begin{array}{l}\text { There is no financial } \\
\text { subsidy for any } \\
\text { alternative mode and } \\
\text { SOV or other mode } \\
\text { parking is free. }\end{array}$ \\
\hline D & $\begin{array}{l}\text { Flexible work } \\
\text { hours }\end{array}$ & $\begin{array}{l}\text { A relaxation in the official daily hours of } \\
\text { business allows employees the flexibility to } \\
\text { adjust their personal work schedules to either } \\
\text { come early/leave early, or come late/leave late } \\
\text { to avoid the most congested portion of daily } \\
\text { commute periods. }\end{array}$ & $\begin{array}{l}\text { This group functions } \\
\text { to shift vehicle trips } \\
\text { out of peak period. }\end{array}$ & $\begin{array}{l}\text { Employees are not } \\
\text { allowed to work on } \\
\text { flexible workhour } \\
\text { schedules. }\end{array}$ \\
\hline
\end{tabular}

While the assumptions of without TDM for the first three groups of TDM strategies are straightforward and consistent with the general understanding of TDM, the assumption for travel cost changes is debatable. The travel cost changes strategies include measures such as imposition of parking fees, differential rates, or discounts for carpool or vanpool parking, and financial incentives or subsidies 
to alternative modes. The differential rates or discounts for carpool or vanpool parking and the financial subsidies to alternative modes are inarguably considered direct results of TDM but there is disagreement on the imposition of parking fees as part of TDM strategies in this specific case study. The major concern is that, no matter if with TDM or without TDM, free parking does not widely exist, especially in Seattle's downtown area.

The assumption of free parking for individual employees only means employees do not have out-of-pocket cost for parking; it may be free for the employer. In other words, it assumes that the imposition of parking fees by the employer on individual employees has a direct impact on their commute model choice. Employees park either in an employer-provided parking facility or in a facility that is not provided by the employer. The employer-provided facility included employer-leased parking space or employer-owned space. In both case, if it is free for the employee, it is not for the employer. Free parking in the parking space that is not provided by the employer means the employee either receives a financial subsidy from the employer to cover the parking cost or enjoys free public parking space. The public parking space that is free for both the employee and employer is a rare situation. According to the 2003 Washington State CTR employer annual report, 50.8 percent of employers charge for SOV parking, 31.2 percent charge for carpool parking, and 11.1 percent charge for vanpool parking.

If only differential rates or discounts for carpool or vanpool parking and financial incentives or subsidies to alternative modes were taken into account, based on the TDM reduced vehicle-trip calculation procedure, the average percentage of vehicle-trip reduction is $\mathbf{1 1 . 3}$ percent. Compared with the original 14.2 percent, it suggests the impact of the imposition of parking fees accounts for a 3 percent reduction in vehicle trips.

The process of estimating VTR was developed based on the COMMUTER model (U.S. Environmental Protection Agency 2005). The impact of each group of strategies is evaluated separately using different methods:

- The impact of alternative work hours is evaluated by adding participants of telecommuting and CWW back to SOVs, then calculating the revised person trips.

- Employer TDM support programs are analyzed using relational factors in look-up tables, along with a normalization procedure applied to the adjusted 
shares to ensure that changes are proportionate across the available alternatives and final choices do not exceed 100 percent.

- Travel cost changes strategies are analyzed through the more rigorous logit pivot-point procedure.

- The impact of flexible work hours is evaluated by estimating the number of vehicle trips shifted out of the peak period due to the program.

The results included changes in traffic flow at each ramp and the ramp ID for each reduced trip if using the $1-5$ portion of the study area. To use CORSIM in evaluating the impacts of TDM, a course of action was developed to calculate changes in traffic flow due to the implementation of a TDM program for each entry and exit ramp of the I-5 study area based on the Washington State CTR database. A methodology was developed to estimate the volume of VTR by TDM, programs implemented at each worksite within the study area can be summarized as follows:

- The percentage of non-SOV trips from each origin (home) to all destinations (worksites) was calculated based on the CTR employee survey data.

- Each reduced trip at an employer site was distributed between worksite and home traffic zones pairs based on the assumption that VTRs were derived from the non-SOV trips.

- Based on the 2000 Tiger/Line road census data, a transportation network of five counties including King, Island, Snohomish, Kitsap, and Pierce was created to find the shortest path for each home-worksite pair and to assign the reduced traffic onto network links based on the all-or-nothing traffic assignment approach.

Table 2 provides selected statistics of the data input into CORSIM. While the average change in traffic flow on $1-5$ ramps is about 4 percent, the distribution of the change is not even. At the AM-peak period, work trips flow from north and south to the downtown area. The biggest flow change for the on-ramps is more than 10 percent and for the off-ramps is almost 50 percent. The average change in traffic flow change for the off-ramps at the downtown area is more than 30 percent.

At the PM-peak period, commuters going home from the downtown area are traveling to both north and south ends. Traffic flow changes at both south and north ends for the on-ramps and the off-ramps in the downtown area are signifcant. The biggest flow changes for off-ramps and on-ramps are more than 10 and 55 percent, respectively. The average change in traffic flow for the on-ramps at the downtown area is more than 20 percent. 
Table 2. Selected CORSIM Inputs

\begin{tabular}{|l|l|l|}
\hline Total Number of Worksite & \multicolumn{2}{|l|}{189} \\
\hline Total number of affected employees working 6am-9am & \multicolumn{2}{|l|}{} \\
\hline Total number of reduced vehicle trips & 5,149 \\
\hline Average percentage of TDM vehicle-trip reduction & $14.2 \%$ & \multicolumn{1}{|l|}{} \\
\hline & \multicolumn{1}{|l|}{} \\
\hline Average share of SOV & With TDM & Without TDM \\
\hline Average share of transit & $56.9 \%$ & $64.5 \%$ \\
\hline Total number of person trips & $28.1 \%$ & $20.4 \%$ \\
\hline Total number of vehicle trips & 54,459 & 54,997 \\
\hline & 34,860 & 40,009 \\
\hline Total number of reduced vehicle trips for I-5 & AM-Peak Period & PM-Peak Period \\
\hline Total I-5 ramp traffic flow & 4,142 & 3,815 \\
\hline Average percentage of I-5 ramp traffic flow change & 99,648 & 109,437 \\
\hline
\end{tabular}

\section{Performance Measures}

The findings showed a significant reduction in recurring delay, a reduction in spatial and temporal extent of congestion, and lesser emissions due to TDM programs. In addition, TDM programs resulted in fuel savings, VMT reduction, and an increase in the average speed of the corridor. These results indicate that TDM had significant impact on the performance of the transportation corridor. The following sections detail the definition of each performance measure and the analysis results.

Recurring Delay. Recurring delay is the cumulative delay encountered by all the vehicles on a section of roadway during a predefined period. Delay is calculated as the actual time taken by a vehicle to traverse a section of roadway minus the time it would have taken if it were traveling at free-flow speed. Figures 2 and 3 compare the $A M$ recurring delay for the scenario with TDM versus the scenario without TDM for NB I-5 and SB 1-5, respectively. 


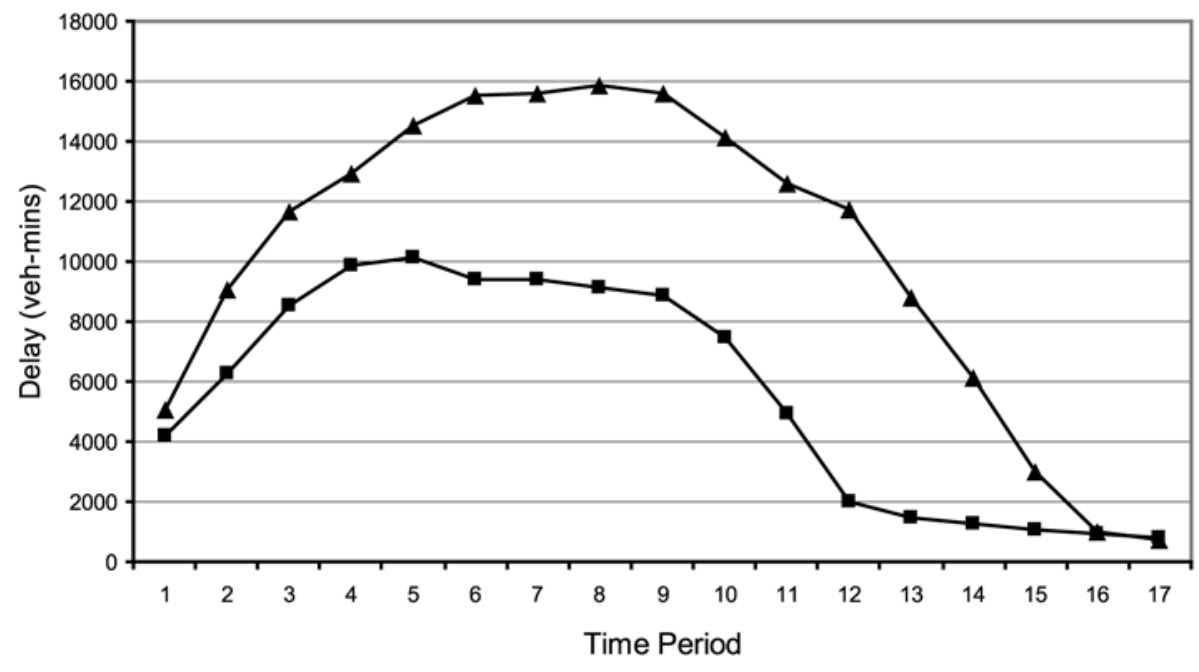

$\rightarrow$ Scenario A (with TDM) $\leftarrow$ Scenario B (without TDM)

Figure 2. AM Recurring Delay on NB I-5

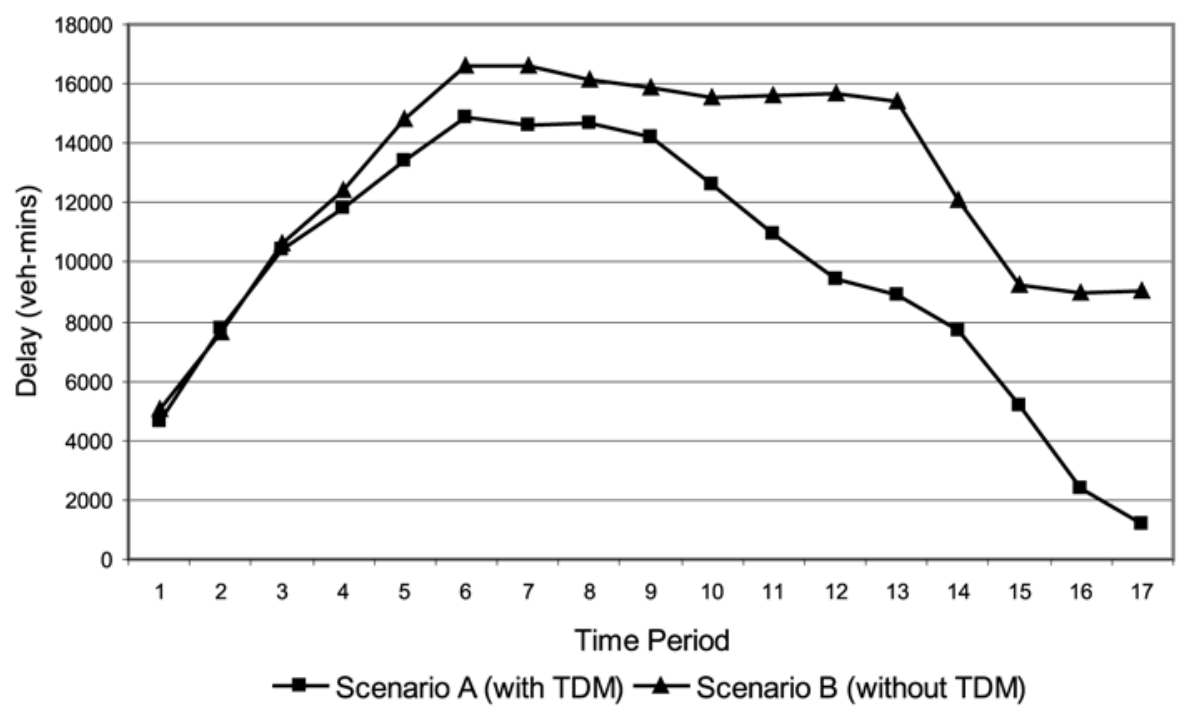

Figure 3. AM Recurring Delay on SB I-5 
Figures 4 and 5 compare the PM recurring delay for the scenario with TDM versus the scenario without TDM for NB I-5 and SB I-5, respectively.

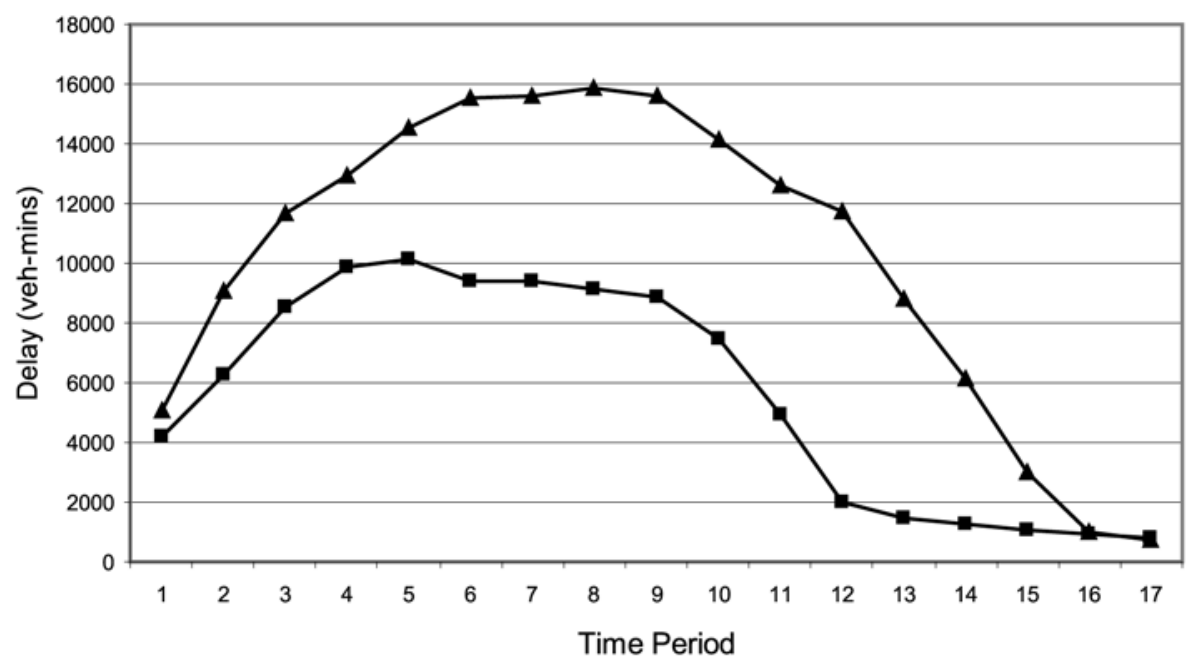

$\rightarrow-$ Scenario A (with TDM) $\longleftarrow$ Scenario B (without TDM)

Figure 4. PM Recurring Delay on NB I-5

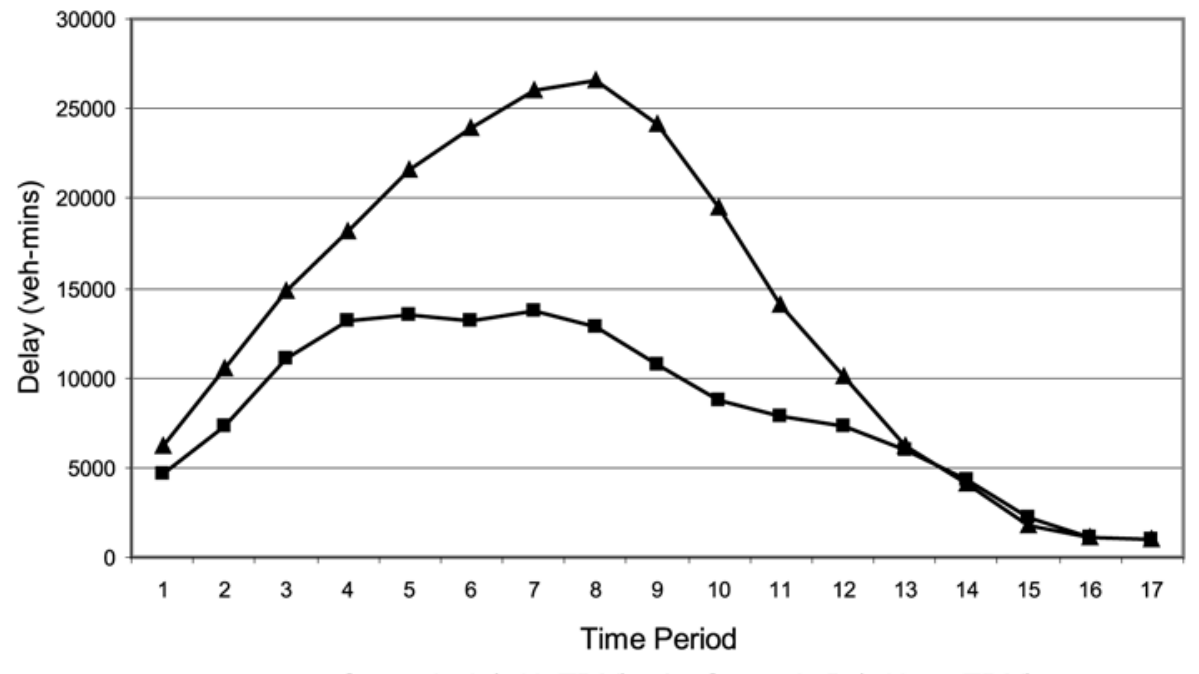

$\rightarrow-$ Scenario A (with TDM) $\longleftarrow$ Scenario B (without TDM)

Figure 5. PM Recurring Delay on SB I-5 
The increase in delay in the scenario without TDM was significant for the entire PM periods, except for the last 15-minute interval on NB and the last 45 minutes on the SB. The without TDM scenario had more recurring delay of 169,486 vehicle minutes during PM period and 152,489 vehicle minutes during the AM period, compared to the scenario with TDM.

Spatial Extent of Congestion on the Corridor. The spatial extent of congestion is the length of roadway within a predefined area and period for which the average travel times are 30 percent longer than the unconstrained travel time. Unconstrained travel time is the time it takes for a motorist to traverse a roadway section when traveling at the free-flow speed of $65 \mathrm{mph}$. If the travel speed were $50 \mathrm{mph}$ or lower, it would take 30 percent longer to travel the same distance when compared with a speed of $65 \mathrm{mph}$. Spatial congestion was measured in lane-miles of the network with speeds lower than the corresponding congested speed. The travel time on a link during a particular time period was calculated to determine the level of congestion on the network. The lane-miles of congested links were added to determine the total lane-miles of congestion on the network during a particular period.

The cumulative spatial congestion for AM-peak periods increased from 442.7 lanemiles in the scenario with TDM to 544.4 lane-miles in the scenario without TDM, where it took 30 percent longer or more than unconstrained travel time. The spatial congestion cumulative for all the periods increased from 324.2 lane-miles for scenario A to 467.1 lane-miles for scenario $B$ during the PM periods, where it took 30 percent longer or more than unconstrained travel time (see Table 3 ).

Temporal Extent of Congestion on the Corridor. The temporal extent of congestion is the "time duration" during which more than 20 percent of the roadway sections in a predefined area are congested as defined by "spatial extent of congestion." One period is considered as the "time duration"; therefore, if 20 percent of the network is congested for a particular period, that particular time period is considered congested. During the AM peak, the temporal extent of congestion increased by 31 percent in the scenario without TDM, as compared to that with TDM at the level of congestion of 30 percent longer or more than the unconstrained travel time (see Table 4). 
Table 3. Spatial Extent of Congestion

\begin{tabular}{|c|c|c|c|c|c|c|c|}
\hline \multicolumn{8}{|c|}{ Spatial Congestion - Lane Miles } \\
\hline \multicolumn{4}{|c|}{ AM-Peak Period } & \multicolumn{4}{|c|}{ PM-Peak Period } \\
\hline From & To & $\begin{array}{l}\text { With } \\
\text { TDM }\end{array}$ & $\begin{array}{c}\text { Without } \\
\text { TDM }\end{array}$ & From & To & $\begin{array}{l}\text { With } \\
\text { TDM }\end{array}$ & $\begin{array}{l}\text { Without } \\
\text { TDM }\end{array}$ \\
\hline $6: 00$ & $6: 15$ & 21.0 & 21.0 & $3: 00$ & $3: 15$ & 12.4 & 22.3 \\
\hline $6: 15$ & $6: 30$ & 32.5 & 29.4 & $3: 15$ & $3: 30$ & 22.8 & 27.4 \\
\hline 6:30 & $6: 45$ & 34.9 & 35.5 & $3: 30$ & $3: 45$ & 29.8 & 32.9 \\
\hline $6: 45$ & 7:00 & 35.5 & 36.2 & $3: 45$ & $4: 00$ & 27.4 & 33.9 \\
\hline $7: 00$ & $7: 15$ & 36.4 & 37.5 & 4:00 & $4: 15$ & 35.2 & 44.5 \\
\hline $7: 15$ & $7: 30$ & 35.4 & 34.8 & $4: 15$ & $4: 30$ & 29.8 & 43.5 \\
\hline $7: 30$ & $7: 45$ & 36.4 & 34.2 & $4: 30$ & $4: 45$ & 32.1 & 45.0 \\
\hline $7: 45$ & $8: 00$ & 34.2 & 34.2 & $4: 45$ & $5: 00$ & 31.6 & 45.0 \\
\hline $8: 00$ & $8: 15$ & 32.7 & 32.7 & $5: 00$ & $5: 15$ & 23.8 & 41.3 \\
\hline $8: 15$ & $8: 30$ & 30.8 & 34.2 & $5: 15$ & $5: 30$ & 20.7 & 33.3 \\
\hline $8: 30$ & $8: 45$ & 31.9 & 34.2 & $5: 30$ & $5: 45$ & 19.0 & 31.1 \\
\hline $8: 45$ & $9: 00$ & 29.7 & 34.2 & $5: 45$ & $6: 00$ & 13.6 & 24.5 \\
\hline 9:00 & $9: 15$ & 19.2 & 34.2 & $6: 00$ & $6: 15$ & 13.0 & 22.1 \\
\hline $9: 15$ & $9: 30$ & 14.1 & 32.3 & $6: 15$ & $6: 30$ & 6.3 & 10.9 \\
\hline $9: 30$ & $9: 45$ & 12.0 & 29.7 & $6: 30$ & $6: 45$ & 5.4 & 8.0 \\
\hline $9: 45$ & $10: 00$ & 5.4 & 27.9 & $6: 45$ & $7: 00$ & 0.7 & 0.7 \\
\hline $10: 00$ & $10: 15$ & 0.7 & 22.0 & $7: 00$ & $7: 15$ & 0.7 & 0.7 \\
\hline \multicolumn{2}{|l|}{ Total } & 442.7 & 544.4 & \multicolumn{2}{|l|}{ Total } & 324.2 & 467.1 \\
\hline \multicolumn{3}{|c|}{$\%$ increase } & $23 \%$ & \multicolumn{3}{|c|}{$\%$ increase } & $44 \%$ \\
\hline
\end{tabular}


Table 4. Temporal Extent of Congestion

\begin{tabular}{|c|c|c|c|c|c|c|c|}
\hline \multicolumn{8}{|c|}{ Temporal Congestion-Vehicle Minutes } \\
\hline \multicolumn{4}{|c|}{ AM-Peak Period } & \multicolumn{4}{|c|}{ PM-Peak Period } \\
\hline From & To & $\begin{array}{l}\text { With } \\
\text { TDM }\end{array}$ & $\begin{array}{l}\text { Without } \\
\text { TDM }\end{array}$ & From & To & $\begin{array}{l}\text { With } \\
\text { TDM }\end{array}$ & $\begin{array}{c}\text { Without } \\
\text { TDM }\end{array}$ \\
\hline 6:00 & 6:15 & 15.0 & 15.0 & 3:00 & 3:15 & 0.0 & 15.0 \\
\hline $6: 15$ & 6:30 & 15.0 & 15.0 & $3: 15$ & $3: 30$ & 15.0 & 15.0 \\
\hline $6: 30$ & $6: 45$ & 15.0 & 15.0 & $3: 30$ & $3: 45$ & 15.0 & 15.0 \\
\hline $6: 45$ & 7:00 & 15.0 & 15.0 & $3: 45$ & 4:00 & 15.0 & 15.0 \\
\hline 7:00 & 7:15 & 15.0 & 15.0 & 4:00 & 4:15 & 15.0 & 15.0 \\
\hline $7: 15$ & $7: 30$ & 15.0 & 15.0 & $4: 15$ & $4: 30$ & 15.0 & 15.0 \\
\hline $7: 30$ & $7: 45$ & 15.0 & 15.0 & $4: 30$ & $4: 45$ & 15.0 & 15.0 \\
\hline $7: 45$ & $8: 00$ & 15.0 & 15.0 & $4: 45$ & $5: 00$ & 15.0 & 15.0 \\
\hline $8: 00$ & $8: 15$ & 15.0 & 15.0 & $5: 00$ & $5: 15$ & 15.0 & 15.0 \\
\hline $8: 15$ & $8: 30$ & 15.0 & 15.0 & $5: 15$ & $5: 30$ & 15.0 & 15.0 \\
\hline $8: 30$ & $8: 45$ & 15.0 & 15.0 & $5: 30$ & $5: 45$ & 15.0 & 15.0 \\
\hline $8: 45$ & $9: 00$ & 15.0 & 15.0 & $5: 45$ & $6: 00$ & 0.0 & 15.0 \\
\hline 9:00 & 9:15 & 15.0 & 15.0 & $6: 00$ & $6: 15$ & 0.0 & 15.0 \\
\hline $9: 15$ & $9: 30$ & 0.0 & 15.0 & $6: 15$ & $6: 30$ & 0.0 & 0.0 \\
\hline $9: 30$ & $9: 45$ & 0.0 & 15.0 & $6: 30$ & $6: 45$ & 0.0 & 0.0 \\
\hline $9: 45$ & $10: 00$ & 0.0 & 15.0 & $6: 45$ & $7: 00$ & 0.0 & 0.0 \\
\hline $10: 00$ & $10: 15$ & 0.0 & 15.0 & 7:00 & $7: 15$ & 0.0 & 0.0 \\
\hline \multicolumn{2}{|l|}{ Total } & 195.0 & 225.0 & \multicolumn{2}{|l|}{ Total } & 324.2 & 467.1 \\
\hline \multicolumn{3}{|c|}{$\%$ increase } & $31 \%$ & \multicolumn{3}{|c|}{$\%$ increase } & $30 \%$ \\
\hline
\end{tabular}


Average Speed. The average speed for the corridor was calculated for each of the 17 periods. Figure 6 shows the average speed of the network for AM period for the scenario with TDM versus the scenario without TDM. The average speed is lower for all periods for the scenario without TDM, and the difference between the average speeds is more significant from 8:30 AM onwards. The difference in average speed ranges from $2 \mathrm{mph}$ to $19 \mathrm{mph}$ for different periods.

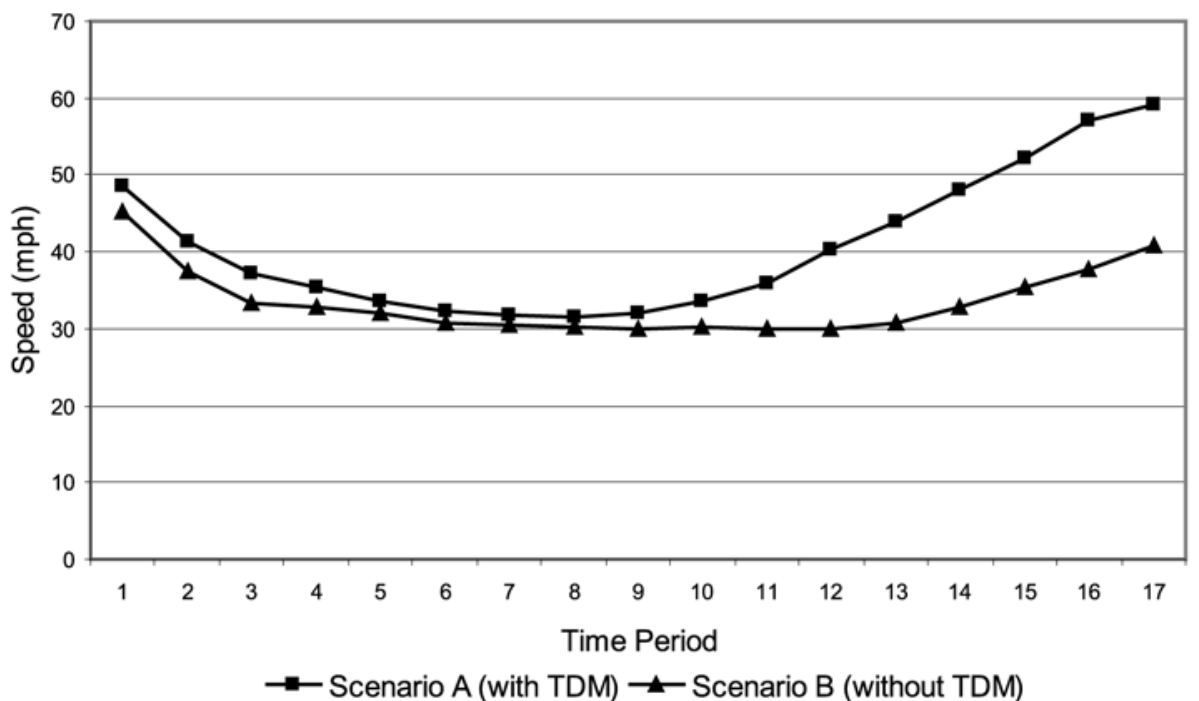

\section{Figure 6. Average Corridor Speed during AM Peak}

Figure 7 shows the average speed of the corridor for the PM period for the scenario with TDM versus the scenario without TDM. The average speed is higher for the scenario with TDM for all periods. The difference in the average speed is more significant between 4:00 PM and 6:00 PM. The difference in average corridor speed varies from 11 to $0 \mathrm{mph}$. 


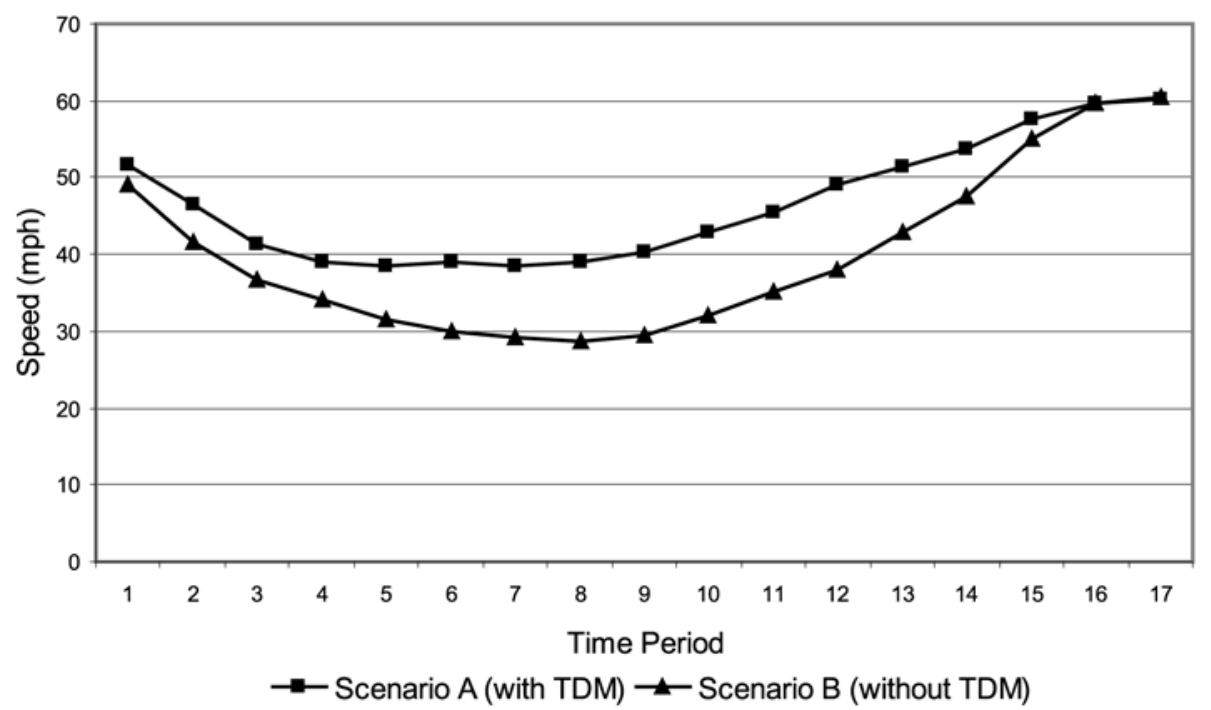

Figure 7. Average Corridor Speed during PM Peak

Fuel Consumption and Emissions. CORSIM provides fuel consumption and emissions statistics for each vehicle on the network. These statistics are accumulated for each period of the analysis. Figures 8 and 9 show the fuel consumption for both scenarios for AM period and PM period, respectively. During the AM period, the scenario without TDM had significantly more fuel consumption for periods after 8:00 AM as compared to that with TDM. During the PM period, this difference in fuel consumption occurred between 4:00 PM to 6:00 PM. The scenario without TDM had 3,489 gallons of excess fuel consumption during AM period and 4,314 gallons during the PM period. 


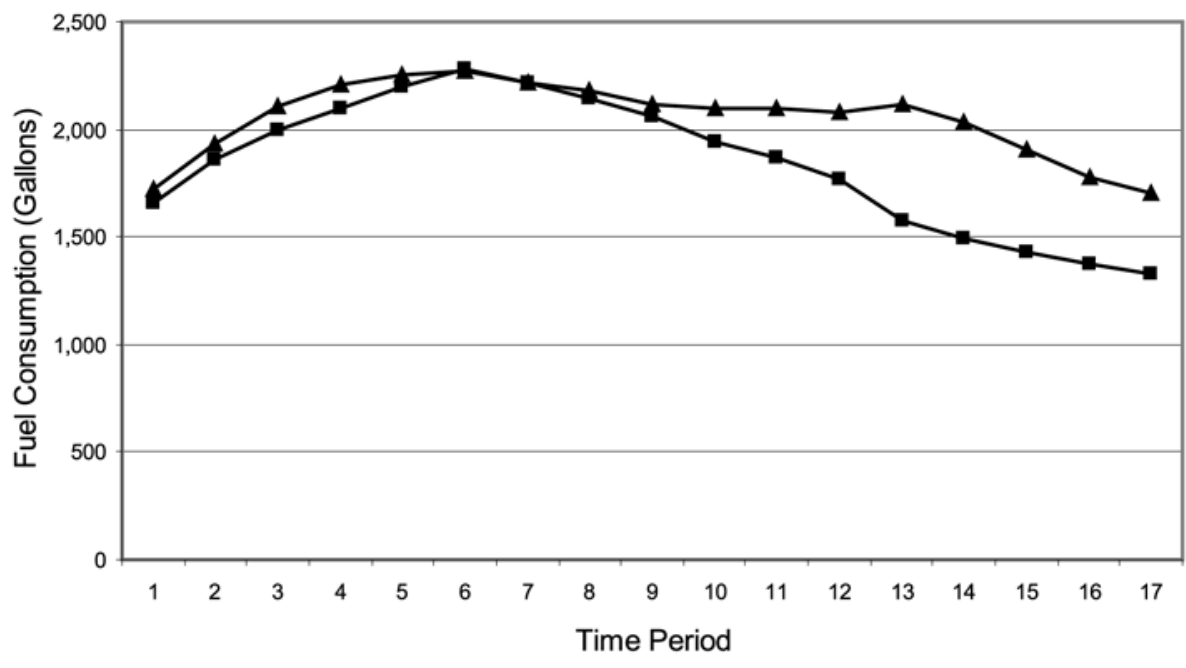

$\rightarrow-$ Scenario A (with TDM) $\longleftarrow$ Scenario B (without TDM)

Figure 8. Fuel Consumption during AM Peak

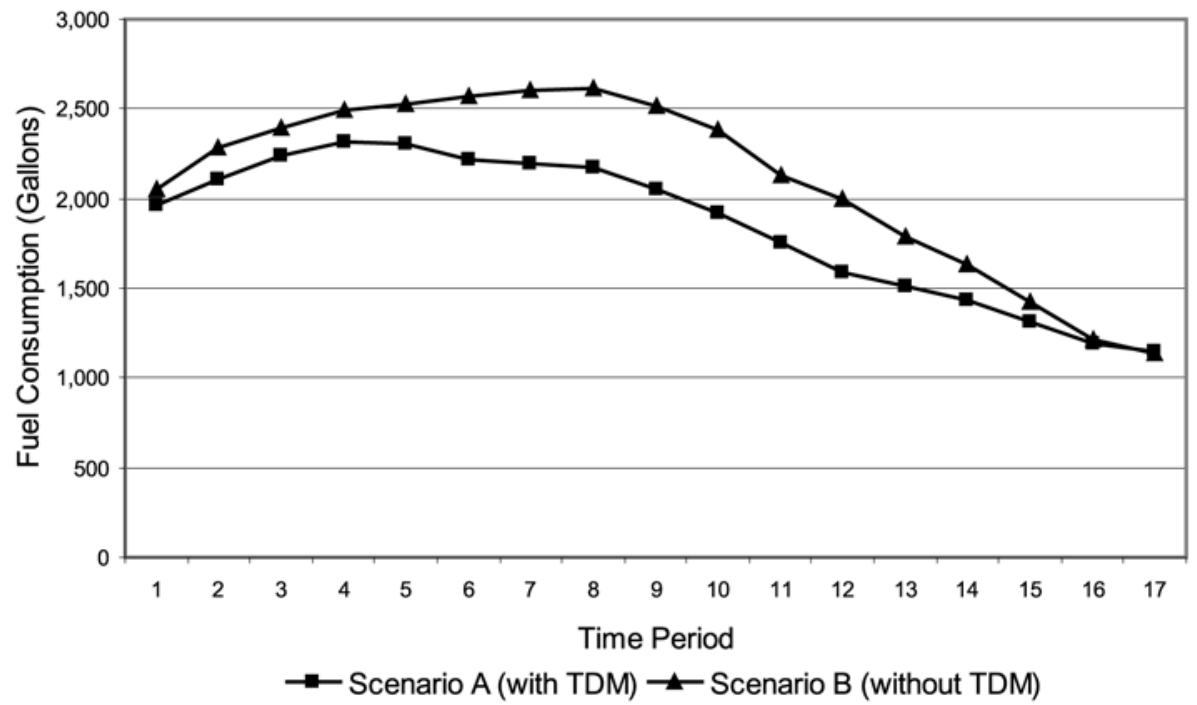

Figure 9. Fuel Consumption during PM Peak 
CORSIM provides hydrocarbons ( $\mathrm{HC})$, carbon monoxide (CO), and oxides of nitrogen (NOx) emission statistics for each vehicle on the network. These values were compared for the scenario with TDM versus the scenario without TDM, as seen in Tables 5 and 6 for AM period and PM period, respectively. Table 5 shows an increase in $\mathrm{HC}$ emissions by 10.3 percent, $\mathrm{CO}$ emissions by 9.6 percent, and NO emissions by 8.9 percent for the scenario without TDM as compared to with TDM during the AM period.

Table 5. Emissions during AM Peak

\begin{tabular}{|l|c|c|c|c|}
\hline Pollutant & $\begin{array}{c}\text { With } \\
\text { TDM }\end{array}$ & $\begin{array}{c}\text { Without } \\
\text { TDM }\end{array}$ & $\begin{array}{c}\text { Added } \\
\text { Emissions }\end{array}$ & $\begin{array}{c}\text { Percentage } \\
\text { Increase }\end{array}$ \\
\hline HC emissions (Kg) & 159.0 & 175.4 & 16.4 & 10.3 \\
\hline CO emissions $(\mathrm{Kg})$ & 11563.5 & 12672.7 & 1109.2 & 9.6 \\
\hline NOx emissions $(\mathrm{Kg})$ & 608.6 & 662.9 & 54.3 & 8.9 \\
\hline
\end{tabular}

Table 6 shows an increase in HC emissions by $21.7 \mathrm{~kg}$, CO emissions by $1,545.1 \mathrm{~kg}$, and NO emissions by $67.9 \mathrm{~kg}$ for the scenario without TDM as compared to that with TDM during the PM period.

Table 6. Emissions during PM Peak

\begin{tabular}{|l|c|c|c|c|}
\hline Pollutant & $\begin{array}{c}\text { With } \\
\text { TDM }\end{array}$ & $\begin{array}{c}\text { Without } \\
\text { TDM }\end{array}$ & $\begin{array}{c}\text { Added } \\
\text { Emissions }\end{array}$ & $\begin{array}{c}\text { Percentage } \\
\text { Increase }\end{array}$ \\
\hline HC emissions $(\mathrm{Kg})$ & 165.4 & 187.1 & 21.7 & 13.1 \\
\hline CO emissions $(\mathrm{Kg})$ & 12170.8 & 13715.9 & 1545.1 & 12.7 \\
\hline NO emissions $(\mathrm{Kg})$ & 625.2 & 693.1 & 67.9 & 10.9 \\
\hline
\end{tabular}

\section{Conclusions}

The employer-based CTR programs in the Seattle area had a significant impact on traffic congestion, travel delay, fuel savings, and emissions. Savings in delay amounted to 152,489 and 169,486 vehicle-minutes for the AM and PM periods, respectively. There was a reduction of 101.7 lane-miles of spatial congestion in the AM peak and 142.9 lane-miles in the PM peak. A significant congestion reduction of 60 and 45 minutes for the AM and PM peaks, respectively, was observed from 
the CORSIM output files. The average speed increased by up to $19 \mathrm{mph}$ for the AM and up to $11 \mathrm{mph}$ for the PM peak. VMT reductions ranged from 17,297 vehiclemiles in the $A M$ peak to 14,511 vehicle-miles in the PM peak. Fuel savings of 3,489 gallons during the $A M$ peak period and 4,314 gallons during the $P M$ periods were direct results of TDM programs. HC emissions reductions of 16.4 and 21.7 kilograms for the AM and PM peak, respectively, are a considerable improvement to air quality, as are emissions reduction of 1,109 and 1,545 kilograms of $\mathrm{CO}$ for the AM and PM peak, respectively.

The research study combined two common goals of transportation agencies: reducing traffic congestion and improving the efficiency of the existing transportation system. By monitoring, evaluating, and communicating TDM strategies and their combined impacts on the roadway system, planners, traffic operations staff, TDM professionals, decision makers, and elected officials can be talking the same language when comparing available cost-effective measures to reduce congestion with a focus on performance, not a given solution.

The research used the language of traffic operations professionals to communicate the impacts of TDM strategies. In the future, data can be collected by intelligent transportation systems (ITS) to help improve the methodology of assessing the impacts on TDM on the total system, not just a corridor. Since ITS is systematically used for dynamic data collection, it can be utilized in before- and after-TDM evaluations.

Furthermore, the impacts of TDM programs were measured using the performance measures indicated by the NTOC performance measure initiative. This aids in communicating the impacts of TDM programs to traffic operations professionals and decision makers.

With respect to future research, this study sets a foundation for work on:

- development of national standards for measuring the performance of TDM that integrate with other transportation systems measures

- development of cost/benefit analysis of TDM programs to communities and businesses

- measuring the impact of TDM programs on freeways, arterials, and surface streets

- analyzing the additive or multiplicative effects of combining different TDM strategies with appropriate ITS applications locally and regionally 
Another area for future research is the synergistic effects of TDM and ITS strategies. For example, on a given corridor, are the effects of implementing a 511 system with HOV lanes equal to the sum of the individual effects of each application or does combining these strategies have a multiplicative effect that could result in larger or smaller impacts?

\section{References}

Brown, Jeffrey, Daniel Baldwin Hess, and D. Shoup. 2003. Fare-free public transit at universities: An evaluation. Journal of Planning Education and Research 23 (1), 69-82. University of California-Berkeley, CA.

Center for Urban Transportation Research, University of South Florida. 1999. Commuter Assistance Program evaluation manual. Florida Department of Transportation. http://www.nctr.usf.edu/clearinghouse/pdf/capman\%20rev\%202.pdf.

Commute Trip Reduction Task Force. 2005. Report to the Washington State Legislature. Accessed February 13, 2007 at http://www.wsdot.wa.gov/NR/ rdonlyres/172087A9-85D1-416B-86C4-33281C7BDE68/0/CTR_Report_ 05.pdf.

General Administration Services (GAO). 2005. The status of telework in the federal government. http://www.telework.gov/documents/tw_rpt05/status-intro. asp.

Hagelin, Christopher, and Jennifer Perone. 2005. 2004 Evaluation of South Florida Commuter Services. Center for Urban Transportation Research. University of South Florida (July).

National Transportation Operations Coalition. 2005. Performance measure initiative final report (July). Accessed August 2006 at http://www.ntoctalks.com/ ntoc/ntoc_final_report.pdf.

Schrank, D., and T. Lomax. 2005. Annual urban mobility report. College Station, TX: Texas Transportation Institute.

Schrank, D., and T. Lomax. 2003. Annual urban mobility report. College Station, TX: Texas Transportation Institute.

United States Environmental Protection Agency. 2005. Commuter model v2.0 user manual. Accessed June 2006 at http://www.epa.gov/otaq/stateresources/ policy/transp/commuter/commuter-v20.zip. 


\section{About the Authors}

NeVine Labib GeorGgi (georggi@cutr.usf.edu) joined CUTR in 1993 as CUTR Resource and Information Center Coordinator. As a research associate in the Transportation Demand Management Team, she investigates the impacts of employerbased policies and programs on the transportation system. Currently, Ms. Georggi is researching impacts of ITS applications in collecting travel data, providing travelers with pertinent feedback to reduce drive-alone use, and enhancing the transit rider experience. She is also researching impacts of employing new technology, in advanced public transportation systems and advanced traveler information systems, on travel behavior.

Over the past 18 years, Ms. Georggi has also participated in designing ITS planning and integration guidebooks for the state of Florida, alcohol-related safety research, travel behavior, travel-related statistical analysis, trip generation models, transportation survey design and analysis, project development and environmental studies, web-interfaced searchable solution database, and transportation resource information center. She holds an M.S.C.E. from the University of South Florida (2000) and a B.S.C.E. from Cairo University (1984).

PhILIP L. WinTers (winters@cutr.usf.edu) joined CUTR as TDM program director in 1993. He has more than 25 years of experience with TDM research, planning, operations, training, and evaluation. Prior to joining CUTR, he worked in corporate relocation and TDM consulting, and directed a regional nonprofit TDM program in Virginia. Among his program's recent accomplishments are the development of the Transportation Management Association Handbook, Vanpool Pricing and Financing Guide, and Worksite Trip Reduction Model and Manual. He manages the National TDM and Telework Clearinghouse, and cohosts the "Learn More. Travel Less" netconference series in partnership with the Association for Commuter Transportation (ACT), which has connected as many as 150 attendees in 15 locations at one time. He also created the TRANSP-TDM listserv, which has more than 1,000 subscribers.

Mr. Winters is a member of the Transportation Research Board's Committee on Transportation Demand, past editor of ACT's TDM Review for five years, and member of the Institute of Transportation Engineers' Transportation Planning Council Executive Committee. 
SACHIN RAJ (rai@cutr.usf.edu) joined CUTR as research associate in March 2005. Mr. Rai has been involved in research related to traffic simulation, traffic operations and safety, and intelligent transportation systems. He has worked on the development of transit signal priority, control strategies, and modeling tools. He has used traffic simulation to develop a model for evaluation of corridors based on traffic, geometric, and transit parameters that affect transit priority. Other areas of his research include traffic signal operations and adaptive traffic control and traffic.

He is actively involved with the Institute of Transportation Engineer (ITE) intelligent traffic signals operations committee. He holds a master of science degree in civil engineering from Michigan State University and a bachelor of technology degree in civil engineering from Institute of Engineering and Technology, India.

LIREN ZHOU (Izhou@cutr.usf.edu) joined CUTR as a graduate research assistant in 2004. He is currently pursuing his Ph.D. in transportation planning and modeling in the Department of Civil and Environmental Engineering at the University of South Florida (USF). Prior to joining CUTR, he worked as a transportation planner at Gannett Fleming, Inc., in Florida and as a mechanical engineer in China. He is an associate member of ITE. He holds a M.S. in civil engineering from USF. 